\title{
REFLEJOS DEL MULTICULTURALISMO MEDIEVAL: LOS TRES ALFABETOS PARA LA NOTACIÓN DEL IBERORROMANCE
}

Uno de los aspectos más interesantes del multiculturalismo medieval, y de su irradiación a épocas posteriores, se manifiesta en el hecho de que el iberorromance aparece escrito en tres diversos alfabetos -el latín, el árabe y el hebreo- ligado cada uno con una determinada lengua de cultura y civilización religiosa. Es significativo además que, si prescindimos de las glosas y de frases sueltas en documentos notariales, los primeros documentos lingüísticos - las jarchas andalusies - vienen escritos en los alfabetos árabe y hebreo respectivamente. Por supuesto, se trata aún de transcripciones rudimentarias del iberorromance, empleadas únicamente dentro del contexto del particular género literario mixto e híbrido del que forman parte las jarchas.

Es en la España cristiana donde, junto al alfabeto latino, el empleo del hebreo y del árabe para la transcripción de textos iberorromances llega a tener un alcance comunicativo menos especializado dentro de las comunidades minoritarias. Es sabido que durante el lento proceso de la Reconquista, musulmanes y hebreos arabófonos cayeron, cada vez más, bajo la dominación cristiana y desarrollaron una vida cultural propia e intensa en sus respectivas aljamas: las juderías y las morerías. A pesar de sus particularismos y tradiciones propias, dichas comunidades minoritarias llegaron gradualmente a romanizarse lingüísticamente; sin embargo, su afán de salvar, por lo menos, el recuerdo de su pasado lingüístico, y su intento de expresar su propia individualidad, da lugar al nacimiento de las literaturas aljamiadas en caracteres árabes y hebreos. Mientras la primera florece principalmente durante el siglo XVI, la escrita en caracteres hebreos tiene sus raíces en la Edad Media, y continúa, incluso, después de la expulsión de los judíos en 1482, hasta nuestros días.

Aparte del interés que los casos de multialfabetismo tienen en su cualidad de fenómenos histórico-culturales, la comparación de varios sistemas alfabéticos, aplicados a la misma lengua, permite también su estudio desde el punto de vista lingüístico. El que las literaturas aljamiadas aparezcan revestıdas de un ropaje exótico -el 
aspecto externo en sí- no justificaría tal interés, ya que sólo afecta el plano del significante de los grafemas. Tratándose, sin embargo, de diferentes sistemas de escritura, la relación de los grafemas entre sí, y su adecuación con las unidades constitutivas de la lengua, pueden estructurarse de maneras muy diferentes, imprimiendo, por lo tanto, una particular fisonomía a las varias modalidades de la lengua escrita.

En principio, o por lo menos en su intención, los sistemas alfabéticos tratan de reproducir mediante signos ópticos el sistema fonológico de la lengua. Sin embargo, todos los sistemas de escritura, por más que se acerquen a tal idea, sufren, en más o menos grado, interferencias basadas en otros criterios, en su mayor parte extralingüísticos ${ }^{1}$. Por otra parte, los sistemas alfabéticos no parecen intentar la transcripción fiel y completa del sistema fonológico de una determinada lengua, sino que más bien se limitan a representar subsistemas seleccionados del sistema fonológico completo². Así, en vez de transcripciones exactas, sería más acertado hablar de diversas interpretaciones grafemáticas de la lengua. Cada sistema de escritura tiene, por consiguiente, una estructura propia que determina sus potencialidades inherentes, y predestina, en cierto modo, su desarrollo en nuevas aplicaciones. En la transposición a otra lengua, las idiosincrasias del modelo original imprimen su sello al nuevo sistema grafemático, pese a los reajustes inevitables y las originalidades innovadoras de los adaptadores.

En la siguiente comparación de los tres sistemas alfabéticos en su aplicación al español, intentaremos poner de manifiesto algunas de sus características salientes, sin pretender, naturalmente, que nuestra exposición sea exhaustiva y sistemática. La complejidad del tema y el presente estado de nuestras investigaciones no nos permi. ten tampoco prestar la debida atención a los cambiantes estados diacrónicos, ni a las variantes regionales e individuales que forzosamente se hallan en cada uno de los tres sistemas. Nuestro propósito se limita a tratar de descubrir algunas tendencias generales y persistentes dentro de cada sistema, sin atender a fenómenos esporádicos no realizados de una manera consistente.

Una de las diferencias fundamentales entre el sistema de escritura en caracteres latinos y los sistemas en caracteres orientales se relaciona, sin duda, con el grado de parentesto genético que existe entre la lengua modelo, del que se empresta el alfabeto, y la lengua receptora. El que el iberorromance sea derivado directo del latín

\footnotetext{
1 Para un tratamiento exhaustivo sobre la problemática de la lengua escrita, consúltese J. VACHEK, Written language, the Hague, 1973 (Janua linguarum, Ser. crítica, 14), donde se presentan algunos ejemplos ilustrativos (pp.22-26, y 54) de la complicada correspondencia entre lengua y lengua escrita.

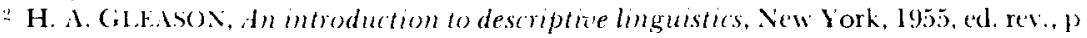
$418, \S 25.18$.
} 
hablado, y el que desde el principio se tenga plena conciencia de su parentesco con el latín escrito, llega a tener profundas consecuencias para el desarrollo de los sistemas de escritura romances. Pese a la evolución de la lengua hablada, los amanuenses de cultura latina no tenían dificultad en relacionar las formas romances con las etimológicas. Además en la Edad Media los romances todavía no alcanzaban la individualidad plena de lenguas nacionales: la lingua romana rustica aún no se concebía como fundamentalmente distinta del latín, sino simplemente como variante funcional de ella. Tal actitud se refleja, por ejemplo, en las obras de Alfonso el Sabio, donde los términos "nuestra lengua" y "nuestro latín" — según el contexto- pueden referirse tanto al latín como al castellano ${ }^{3}$. En sentido análogo, tampoco parecía sentirse la necesidad de distinguir siempre y tajantemente entre las variantes regionales de las lenguas romances. El concepto "lengua" tenía un sentido más amplio y menos preciso, con límites difusos tanto en su extensión sincrónica como en la diacrónica ${ }^{4}$. En vista de tales actitudes, nacidas de las circunstancias histórico-culturales y de la peculiar visión del mundo medieval, los sistemas romances de escritura se desarrollan en estrecho contacto con las convenciones grafemáticas del latín medieval, de modo que en algunos casos resulta incluso difícil hacer una distinción nítida entre ciertos textos latinos medievales corrompidos y los primeros tanteos auténticos de escribir el romance ${ }^{5}$. Por otra parte, el que las fronteras entre los varios romances queden difusas, o por lo menos, inconscientes en la mente de los hablantes, puede, a su vez, contribuir a vacilaciones y formas híbridas en la representación grafemática, a causa de facilitar el intercambio de grafemas. En este contexto interesa también que, en los focos de irradiación culturales, el equipo de amanuenses frecuentemente incluía extranjeros ${ }^{6}$. Estos factores, junto con la influencia del modelo latino, deben tomarse en cuenta para la génesis y desarrollo de los sistemas grafemáticos romances.

${ }^{3}$ HANS-JOSEF NIEDEREHE, Die Sprachauffassung Alfons des Weisen, Tübingen, 1975 (Beih, zur ZRPh, 144), pp. 78-79.

${ }^{4}$ NIEDEREHE, p. 74.

${ }^{5}$ HELMUT LÜDTKE, "Die Entstehung romanischer Schriftsprachen", VR, 23 (1964), pp. 3-21. Véase especialmente la p. 11 donde dice: "Die Einstufung cines Textes in die Kategorien «latenisch», «romanisch», «halbromanisch» erweist sich, wie wir sehen, als undurchfiihrbar, sobald wir mint Grenzfallen zut tun haben".

${ }^{6}$ Es sabido que los ambientes cortesanos de las casas reales tenían, por lo general, un carácter cosmopolita, y la presencia de amanuenses de distinta procedencia en el entourage del monarca sería más bien la regla que la excepción. Piésese, por ejemplo, en la corte de Feterico II en Sicilia. Una situación análoga debía de existir en las scriptoria de los monasterios. En el principio, tales condiciones llevarían a cierta coexistencia de diversas normas lingüísucas y también ortográficas. Por otra parte, I. HAJNAL, en L'enseignement de l'écriture aux universités médiévales, Budapest, 1959, destaca la importancia de las universidades de renombre, especialmente la de la Sorbonne, en la propagación de la escritura. Atrayendo estudiantes de toda Europa, las universidades, sin duda, podían ejercer una influencia 
Prescindiendo del inventario de grafemas, la herencia latina se manifiesta, sobre todo, en grafías etimológicas que, según la época de su origen, pueden dividirse en varios tipos:

1. Las que aparecen ya en los primeros documentos y que podrán llamarse "hereditarias", en vista de que surgen espontáneamente, junto con otras variantes no etimológicas. Aunque hay indicios de que, en los primeros tanteos de transcribir el romance, los amanuenses procuran aproximarse a una notación fonética rudimentaria, tal propósito no se logra del todo. Se debe tomar en cuenta que los amanuenses, originariamente, siguen acostumbrados a redactar documentos en latín medieval en la mayoría de los casos, ensanchándose su actividad sólo poco a poco para incluir también el romance en circunstancias específicas? ${ }^{7}$. Su familiaridad con los textos latinos medievales, y la ya mencionada actitud ambivalente frente a la dicotomía latín-romance, impiden naturalmente un desarrollo independiente de las scriptae romances. En estas circunstancias es natural que la falta de grafemas adecuados para la representación de los nuevos fonemas romances se supliera, a veces, recurriendo a las grafías etimológicas - procedimiento que tiene además la virtud de prestar cierto carácter suprarregional a las diversas scriptae $e^{8}$.

Entre las numerosas y competidoras grafías etimológicas de este primer período se podrían citar casos como $\langle$ gn $\rangle,\langle$ ni $\rangle$ y limitado al ámbito hispánico- también $\langle\mathrm{nn}\rangle$, correspondiendo todas al fonema $/ \mathbf{n} /$. Aunque gradualmente, y según la región, una de estas soluciones tiende a imponerse por extensión analógica ${ }^{9}$, las referencias etimológicas se conservan en casos individuales.

Por otra parte, el hábito de tener presente el modelo latino actúa como freno para un reajuste más conforme al estado fonológico. Así

significativa en el desarrollo de los sistemas grafemáticos de las más diversas lenguas vernaculares.

7 LËDTKE, art. cit., p. 12; MAX PFISTER, "Die Anlänge der altprovenzalischen Schrittsprache" $Z R P h, 86$ (1970), pp. 305-323. Plister menciona que durante el siglo XII, en documentos que contienen contratos entre nobles predomina el uso del latín, mientras en los hechos con representantes de la burguesía predomina cada vez más el uso del provenzal, reflejando el cambio social resultante de la creciente importancia de este estrato social.

${ }^{8}$ Véase la intervención de $M$. Lecoy en la discusión seguida a la ponencia de CHARLEsTHEODORE CoSSEN, "Graphème el phonème: le problème central de l'étude des langues ecrites du moyen âge", Les dialectes de France au moyen âge et aujourd'hui, colloque organisé par le Centre de Philologie et de Littérature romanes de l'Université de Strasbourg du 22 au 25 mai 1967 (Paris, 1972), p. 20, donde dice: "Le problème des scribes était, en effet, de trouver une or thographe commune, que pût être lue par des gens de provenances différentes. Cette orhtographe n'aurait pas rempli son rồle si elle avait été trop fidèle. Pensons au problème actuel des parler occitans. La conservation de l'ortographe latine a eu la grand utilité de rendre les textes écrits compréhensible aux différentes régions: clle n'a donc pas, au départ, une valeur fonctionnelle". Cf. también Pfister, art, cit., pp. 307-308, que alude a la tendencia hacia la creación de normas suprarregionales.

${ }^{9}$ RAMÓN MENÉNDEZ PIDAL. Orígenes del español, 5 "ed., Madrid, 1964, pp. 49-55 (4-5). 
por ejemplo, en el caso de las velares $/ \mathbf{k} / \mathrm{y} / \mathrm{g} /$ latinas, el que su diferente evolución delante de $/ \mathrm{i} / \mathrm{y} / \mathrm{e} /$ - con excepción del sardono afecte su representación gráfica, da por resultado que tanto el grafema $\langle\mathrm{c}\rangle$ como $<\mathrm{g}\rangle$ llegan a ser bivalentes, y se hace además necesaria la adopción de otros símbolos para la representación de $/ \mathrm{k} /$ delante de $/ \mathrm{i} / \mathrm{y} / \mathrm{e} /$. La manera de resolver el reajuste necesario no resulta enteramente uniforme en toda la Romanía; pero, lo que importa aquí es el hecho de que - desde el punto de vista de su representación gráfica- el dilema ocasionado por la diferente evolución del $/ \mathbf{k} /$ latino encuentre soluciones paralelas en las varias lenguas romances, constituyendo así un nexo de índole estructural entre los sistemas de escritura respectivos. En cuanto a las huellas etimológicas, en este estado inicial de la génesis de los textos romances, no creemos, sin embargo, que nos hallemos frente a una consciente preocupación por la etimología, sino más bien parece tratarse de un fenómeno de interferencia, procedente de los modelos latinos, que impide el desarrollo de una notación estrictamente fonológica. Es de considerar, por otra parte, que cada vez más se imponía la necesidad práctica de crear normas de lenguas escritas suprarregionales - meta no siempre compatible con consideraciones fonéticas. La abigarrada variedad de formas que se encuentra en los primeros textos, es, en cierto sentido, un indicio de que se trata de un período de experimentación con diversos criterios en pugna. Para el amanuense el problema consistía en encontrar una solución práctica, sin que se noten indicios de preocupaciones dogmáticas, frecuentes en épocas posteriores.

2. Otros restos de grafías etimológicas, o más bien tradicionales, son el resultado de evoluciones posteriores, y se deben a la inercia de los sistemas grafemáticos que tardan en reflejar los cambios del sistema fonológico. La oposición gráfica entre $\langle\mathrm{b}\rangle \mathrm{y}\langle\mathrm{v}\rangle$, y -en el caso del castellano hablado en la mayor parte de América latina - la de $\langle\mathrm{c}\rangle,\langle\mathrm{z}\rangle \mathrm{y}\langle\mathrm{s}\rangle$ ilustran bien la tendencia conservadora de la escritura, la cual, sin embargo, contribuye a que se impida la fragmentación extrema de las lenguas romances en sus formas escritas. Tal tendencia conservadora, sin embargo sólo puede mantenerse en el contexto de una continuidad de corrientes culturales. Los textos aljamiados, que se enlazan con ámbitos culturales ajenos a la latinidad cristiana, naturalmente, se rigen por otro tipo de convenciones, como veremos más adelante.

3. Por fin, debemos acordarnos de los cultismos gráficos, o relatinizaciones, introducidas en épocas más tardías por prurito académico. Como ejemplos podríamos mencionar la imposición por la Academia en siglo XVIII, de grafías como concepto, efec. to, digno, etc., en lugar de las formas conceto, efeto, dino, usua. les en el Siglo de Oro ${ }^{10}$; la persistencia de las grafías $<\mathrm{ph}>$, 
$<\mathrm{ch}\rangle,\langle\mathrm{rh}\rangle \mathrm{y}<\mathrm{th}\rangle$ en los grecismos ${ }^{11}$; la reintroducción de la $l$ etimológica, junto a una $u$ procedente de $l$ latina, en casos como hault, moult en el francés del siglo $\mathrm{XV}^{12}$; o la sustitución por fin, de las grafías inglesas dette y doute por debt y doubt, con $b$ etimológica ${ }^{13}$.

¿Qué significado debe atribuirse a ese persistente rasgo etimologizante? Sin duda, desde el lado fonológico, tales grafías pueden parecer un lastre a primera vista, disfrazando el estado fonológico presente; pero, gracias a ellas, las lenguas romances se aproximan entre sí mucho más de lo que permitiría una escritura estrictamente fonológica ${ }^{14}$, y se ensanchan las posibilidades comunicativas tanto en el sentido sincrónico como en el diacrónico. Para el conocedor de la lengua, las grafías etimológicas no impiden la correcta interpretación de los fonemas, pero gracias a esta intrusión de criterios extralingüísticos, desde el punto de vista de cualquier hablante de una lengua romance, la lectura de las otras se facilita sobremanera.

Aparte de las tendencias etimologizantes en la grafía, conviene señalar otra característica de las lenguas romances, compartida también por otras del ámbito de la cristiandad occidental. Se trata del empleo de dígrafos. El procedimiento tiene su origen en el latín clásico que introdujo los dígrafos $c h, p h, r h$ y $t h$ para la transcripción de fonemas en palabras griegas llegadas por vía culta ${ }^{15}$. Tales grafías dejaron sus huellas no solamente en las lenguas romances, sino también en otras, como el alemán e inglés. La tendencia de formar dígrafos continuaba durante la Edad Media, cuando siguió empleándose la $h$, letra ociosa ya, para la formación de nuevos dígrafos, como por ejemplo $\langle\mathrm{ch}\rangle=/ \check{c} /$ del ant. fr. y del español, o $<\mathrm{lh}\rangle, \mathrm{y}\langle\mathrm{nh}\rangle=/ \mathrm{n} /$ del provenzal y portugués. Otros dígrafos se relacionan con las grafías etimológicas, como en el caso de los ya mencionados grupos $\langle\mathrm{gn}\rangle$, $\langle\mathrm{ni}\rangle$, y $<\mathrm{nn}\rangle$. Aunque el empleo de dígrafos (y trígrafos) podría darse de una manera independiente en distintos sistemas, en el caso de las lenguas romances es evidente que se trata de un rasgo común que, incluso, por mediación de las lenguas romances, junto con otros calcos gráficos, llega a caracterizar algunas lenguas no romances.

Un caso curioso de esta irradiación de características grafemáticas nos proporciona, por ejemplo, el húngaro -lengua no indoeuropea-, en cuya historia ortográfica temprana se distinguen una época de influencia francesa y otra italiana. En consecuencia, aparecen, entre otros, los dígrafos $\langle\mathrm{gh}\rangle=/ \mathrm{g} /$ delante de $e, i$, de evidente

\footnotetext{
${ }^{11}$ Mientras en España estas grafías se rechazaron a principios del siglo XIX (Lapesa, p. 276), en Portugal perduraron hasta el siglo XX.

12. MARCel CoHeN, Histoire d'une langue: le franģais, Paris, 1967, p. 151.

13 VACHEK, op. cit., p. 48.

14 Véase la nota 8.

15 W. J. ENTWISILE, The Spanish language, London, 1951, p. 153.
} 
origen italiano, y $<\mathrm{ch}\rangle=/ \check{c} /$ de origen francés antiguo. En algunos textos antiguos se dan grafías "pseudoetimológicas" de $\langle\mathrm{c}\rangle$ delante de $e, i$, con valor de $/ \check{c} / 16$.

Como ya apuntamos, el resultado concreto y significativo de estos fenómenos, en el contexto de los romances, consiste en que tanto la tendencia hacia la grafía etimológica como el recurso de los dígrafos contribuyen a que el grado de afinidad entre las lenguas romances escritas sea mayor del que podría explicarse por el mero parentesco genético. Se trata, en principio, de los efectos de un superestrato cultural ${ }^{17}$, del cual la parte grafemática forma sólo un aspecto parcial. Bajo su égida se perfila un Sprachbund ${ }^{18}$, o - ex presión más atinada a nuestros fines limitados- un Schriftbund ${ }^{19}$. Dicho superestrato, cuya acción perdura durante siglos, debe concebirse como dinámico y cambiante. Sus elementos constitutivos son, en primer lugar, las varias modalidades del latín —el clásico, el medieval, y el humanístico- añadiéndose a este acervo común también elementos de los dialectos romances de prestigio. Para ilustrar la influencia de éstos, podemos citar la introducción de las grafías $\langle\mathrm{lh}\rangle=/ \mathrm{l} / \mathrm{y}\langle\mathrm{nh}\rangle=/ \mathrm{n} /$ en Portugal, que llegaron a sustituir a las anteriores, usuales en toda la Península ${ }^{20}$. De origen provenzal, aparecen primero en la cancillería de Alfonso III, rey "afrancesado" y rodeado de trovadores, generalizándose entre 1265 1275 también en los documentos notariales de la región. Como curiosidad apuntamos que la grafía $\langle\mathrm{nh}\rangle=/ \mathrm{n} /$ existía también en la antigua ortografía húngara ${ }^{21}$. A causa del gran prestigio literario del provenzal, y en vista de la separación geográfica de las Schriftlandschften del sur de Francia, Portugal y Hungría, nos

16 Véase la referencia al discurso de J. MELiCH, "A magyar helyesírás", Magyar Nyelv, 4 (1908), p. 328; ISTVAN, Helyesírásunk története a könyonyomtatás koráig, Budapest, 1952, pp. 74-78; GÉZA BÁRCZI, "Influence française dans l'orthographe hongroise du Moyen Âge", $A L B, 1$ (1951/52), pp. 19-63.

17 Para el concepto de superestrato cultural cf. CARlo TAgliavinl, Le origini delle lingue neolatine, $4^{*}$ ed. aggiornata, Bologna, 1964, pp. 272-279 (\$62)

is Según HANS J. VERMEER, Einführung in die linguistische Terminologie, Darmstadt, 1971, p. 27, la primera definición del concepto Sprachbund parece proceder de N. Trubetzkoy, en Proposition 16, Actes du premier Congrès international de Linguistes a la Haye, 1928, Leiden, 1930, p. 18. Como obra de divulgación se menciona HENRIK BECKER, Der Sprachbund, Leipzig-Berlin, 1948.

19 Definimos el Schriftbund como un conjunto de convenciones grafemáticas compartidas por varias lenguas, no relacionadas necesariamente en el sentido genético, siempre que dichas convenciones se aparten de criterios puramente fonológicos, debiéndose su explicación a la actuación de factores culturales. Se debería añadir, sin embargo, que incluso una preocupación consciente de construir un sistema de escritura basado exclusivamente en criterios fonológicos puede tener una base cultural e idológica.

${ }^{20}$ LUIS F. LINDLEY CINTRA, "Observations sur l'orthographe et la langue de quelques textes non littèraires galiciens-portugais de la seconde moitié du XIII ${ }^{e}$ siècle", Les anciens textes romans non littéraires, Colloque international organisé par le Centre de Philologie et de Littératures romanes de l'Université de Strasbourg, 1961 (Paris, 1963), pp. 189-90.

$2 t$ Véase Melich, mencionado en la nota 16. 
inclinamos a explicar estos fenómenos dentro del contexto de un superestrato grafemático complejo que se revitaliza continuamente por la incorporación de nuevos elementos.

En vista de lo que hemos expuesto, resulta evidente que el empleo de un determinado alfabeto implica mucho más que la mera aplicación mecánica de un inventario de grafemas. Por consiguiente, los textos iberorromances escritos en caracteres árabes y hebreos - pese a la posibilidad de influencias del adstrato de los textos escritos en alfabeto latino- representan sistemas independientes, y no meros calcos del sistema autóctono. Revelan una estructura propia, y un individualismo que los separa desde el punto de vista tipológico. Para su comprensión adecuada es preciso partir de sus características originarias, tal como se presentan en su aplicación a textos hebreos y árabes respectivamente. Se trata de sistemas de escritura que, a causa de una evolución parecida, tienen mucha afinidad entre sí, compartiendo las siguientes características, típicas de las escrituras semíticas ${ }^{22}$ : (1) Ausencia de grafemas vocálicos en la etapa primaria; (2) la extensión de ciertos grafemas consonánticos -como alif/aleph, ya/a/yod, y $w \bar{a} w-$ en función secundaria, para la representación de fonemas vocálicos; (3) la introducción de signos diacríticos para la distinción de fonemas, para la geminación, o incluso, para cualidades fónicas no diferenciadoras; (4) la introducción de signos vocálicos, super o infrapuestos a las consonantes.

Pese a las semejanzas que se presentan a primera vista, existen naturalmente, en la aplicación concreta de los mencionados recursos en las diversas escrituras semíticas, diferencias que se deben, en parte, a las diferentes circunstancias históricas vigentes en el momento de su introducción ${ }^{23}$. Así, la fijación del sistema de escritura árabe en su forma plena y definitiva, es coetánea a la cristalización del árabe clásico como lengua literaria suprarregional. En el caso del hebreo, en cambio, los mencionados recursos se introducen mil años después de que el hebreo cesara de ser lengua hablada. Mientras la meta principal del sistema árabe es la expresión grafemática de una norma lingüística, los masoretas del hebreo tratan más bien de facilitar la pronunciación del texto litúrgico a lectores cuya lengua materna ya no es el hebreo. De estos hechos se sigue que el sistema de escritura árabe acaba por estructurarse casi perfectamente a base de criterios fonológicos, con una correspondencia de término a térmi-

22 En nuestras observaciones siguientes nos atenemos a SHELOMO MORAG, The vocalization systems of Arabic, Hebrew, and Aramaic, The Hague, 1972 (Janua Linguarum, 13), pp. 9-12; W. WRIGHT, A grammar of the Arabic languague, $3^{\mathrm{a}}$ ed., Cambridge, 1955, 1, pp. 1-24; FRIEDRICH H. W. GESENIUS, Hebrew grammar, 2" ed., rev., Oxford, 1910, pp. 25-65; HANS-RUDOLF SINGER, "Die arabische Schrift", StG, 18 (1965), pp. 769-778; KHALIL I. H. SEMAAN, "Linguistic view of the development of the Arabic writing system", WZKM, 61 (1967), pp. 22-40.

${ }^{23}$ MORAG, op. cit., pp. 61-69. 
no entre grafemas y fonemas. En contraste, el sistema hebreo tolera grafemas bivalentes, y tiende a representar, en algunos casos, valores puramente fonéticos.

En lo concreto, estas diferencias se manifiestan de la siguiente manera: los grafemas $\left\langle{ }^{\prime}\right\rangle=$ alif, $\langle\mathrm{y}\rangle=y \bar{a}, \mathrm{y}\langle\mathrm{w}\rangle=w \bar{a} w$ del árabe no tienen valor vocálico independiente, y se emplean sólo en la función de letras de prolongación para indicar las vocales largas. Su empleo refleja fielmente el estado fonológico del árabe clásico, en el cual la cantidad vocálica tiene una distinta función diferenciadora. Se admite que representan también valores consonánticos, y -en los casos de $\langle\mathrm{w}\rangle \mathrm{y}\langle\mathrm{y}\rangle-$ semiconsonánticos sirviendo además de letras de soporte. Hay que subrayar, no obstante, que en todas estas varias funciones el contexto grafemático permite una distinción neta y automática en textos vocalizados ${ }^{24}$.

El término empleado para los correspondientes grafemas del hebreo -el de matres lectionis -, no evoca, evidentemente, la idea de prolongación. En efecto, se trata de verdaderas letras vocálicas que se emplean en la llamada scriptio plena, contrastada con la scriptio defectiva que prescinde de la notación de valores vocálicos. Habiéndose perdido en el hebreo bíblico la función diferenciadora de la cantidad vocálica ${ }^{25}$, las "letras vocálicas" sólo representan un recurso anxiliar y algo rudimentario en la interpretación del texto. Se trata de grafemas multivalentes, cuya función diferenciadora, sin embargo, puede precisarse más mediante el uso adicional del sistema de puntuación, introducido más tarde por los masoretas para salvaguardar la interpretación, y, sobre todo, para fijar la pronunciación correcta de los textos sagrados.

Aparte de estas diferencias en la representación vocálica, el sistema de escritura hebreo también difiere del árabe en el empleo de los puntos diacríticos: mientras en éste sirven sólo para la distinción de fonemas, en aquél (caso de las letras $p b t d k \mathrm{~g}$ ) el punto diacrítico no implica necesariamente distinción fonológica, sino variantes en distribución complementaria ${ }^{26}$.

Huelga decir que se debe proceder con cautela al transferir conclusiones sacadas de textos escritos en lengua árabe o hebrea a los aljamiados. No obstante, algunas características de éstos parecen determinarse por las posibilidades ofrecidas de los sistemas origina-

${ }^{24}$ Cf. MORAG, pp. 14 y 20 (§ 1.1.1, y 2.2.3). Cuando van combinados con hamza, los grafemas $\langle\mathrm{w}\rangle \mathrm{y}\langle\mathrm{y}\rangle$ sirven de letras de soporte; provistos de signos vocálicos tienen valor de consonantes; y provistos de sukün - en la representación de diptongos - tienen valor semiconsonántico. En ausencia de tales signos sirven para indicar la prolongación de la cantidad vocálica, la cual tiene siempre en árabe función diferenciadora.

25 J. CANTINEAU, "Essai d'une phonologie de l'hébreu biblique", BSLP, 46 (1950), pp. 82-122. Véase especialmente la p. 122 donde dice: "Le sistème prosodique parait ignorer l'usage différenciatif de la quantité vocalique, mais il fait un emploi assez important des oppositions de place d'accent. . ."; véase también MORAG, op. cit., pp. 107-111 y 122.

26 MORAG, pp. 26-27, 31; CANIINEAl, pp. 100-102. 
dos y su mayor o menor grado de adaptabilidad. Fijándonos ahora en las diferencias más salientes entre los sistemas aljamiados, se nos presentan en los siguientes aspectos: respecto a la representación de las vocales, en el sistema aljamiado islámico, éstas se indican sistemáticamente mediante los signos vocálicos fatha, kasra y damma ${ }^{27}$. En la formación de grafemas consonánticos para representar fonemas típicos del iberorromance, se hace uso de un procedimiento diacrítico: es concreto, del tasdid - signo de geminación en el árabeque llega a tener una función cualitativa en el nuevo contexto.

En cuanto al sistema aljamiado judeo-español, para la representación de las vocales se emplean las matres lectionis, sin recurrir a la vocalización mediante la puntuación masrética, salvo en casos muy esporádicos. Como las tres letras vocálicas del hebreo no bastan para representar las cinco vocales del español, los grafemas $\langle y\rangle$ y $\langle w\rangle$ transcriben las vocales $/ \mathrm{i} / \mathrm{e} / \mathrm{e} / \mathrm{y} / \mathrm{u} / \mathrm{h} / \mathrm{o} /$ respectivamente, correspondiendo además a valores consonánticos y semiconsonánticos. Multivalentes ya en el contexto del hebreo bíblico, la carga funcional que tienen que asimilar en el romance se incrementa considerablemente. Así por ejemplo, el grafema $<\mathrm{y}>$ corresponde a los siguientes valores: $/ \mathrm{e} /, / \mathrm{i} /, / \mathrm{i} /, \mathrm{j} / \mathrm{y} / \mathrm{y} /$. Interviene además en la formación de grafías compuestas para transcribir las palatales $/ \mathrm{n} / \mathrm{y}$ $/ /$, que se forman mediante lamed y nun, seguidos de yod, o, en algunos manuscritos, seguidos de doble yod. Sin embargo, en vista de la multivalencia de $\langle\mathrm{y}\rangle$, las grafías compuestas $\langle$ nyy $\rangle$ y $\langle$ lyy $\rangle$ también se prestan a varias interpretaciones, pudiendo la última - según el contexto- equivale a las grafías latinas $l l, l l e, l l i$, $l e e, l e i, l i e^{28}$. Ya que grafías compuestas (dígrafos o trígrafos) no se conocen en el sistema originario, su presencia en los textos judeo-españoles podría explicarse como influencia del adssrato grafemático latino ${ }^{29}$.

Comparando los dos sistemas aljamiados en cuanto a sus tendencias esenciales, llegamos a las siguientes conclusiones: en el plano del significante, prescindiendo del trazado y de las diferentes formas de los grafemas - que damos por supuesto- su distinta estructuración externa contribuye también al impacto óptico específico. En los textos aljamiados en alfabeto árabe, aparte de la mayor abundancia de signos diacríticos, los signos vocálicos aparecen como externos a la secuencia de grafemas consonánticos, pudiéndose caracterizar como suprasegmentales. En los textos judeo españoles, en cambio, los grafemas vocálicos forman segmentos de la misma secuencia de grafemas. El uso de signos diacríticos se da sólo en po-

27 Fatha $=/ \mathbf{a} / ;$ kasra $=/ \mathbf{i} / ;$ damma $=/ \mathbf{o} /, / \mathbf{u} / ;$ fatha seguido de alif de prolongación $=/ \mathrm{e} /$.

${ }_{28}$ R. FOULCHÊ-DELBOSC, "La transcription hispano-hébraique", RHi, 1 (1894), p. 28.

29 MANUEL ALVAR y JACINTO BOSCH, "Interpretación de un texto oscense en aljamía hebrea", Miscelánea José María Lacarra, Zaragoza, 1968, p. $26(\S 7)$. Los autores citados, con ciertas reservas, admiten tal posibilidad en el texto estudiado por ellos, en vista de la existencia de la grafía $<$ ny $>$ en Aragón, y la de $\langle$ ly $>$ en Cataluña en los textos latinos. 
$\cos \operatorname{casos}^{30}$, y desde el punto de vista visual resulta bastante discreto.

En lo que se refiere a la adecuación entre fonemas y grafemas, la grafía judeo española se aparta del ideal fonológico que aspira a una correspondencia de término a término, apareciendo grafemas multivalentes por una parte, y los dígrafos, o trígrafos, $\left\langle\mathrm{ly}_{\mathrm{y}}\right\rangle,\left\langle\mathrm{lyy}_{\mathrm{y}}\right\rangle$, $<$ ny $\rangle$, $<$ nyy $\rangle$. Se nota además cierta propensión hacia una notación fonética, que se manifiesta en una distinción gráfica entre la $/ \mathrm{d} /$ oclusiva y su variante fricativa $/ \mathrm{d} /{ }^{31}$. Para el grupo $/ \mathrm{ks} /$, aparte del uso menos frecuente de la grafía $k s$, se da por lo general $g s$, conforme a la realización usual de este grupo en el habla ${ }^{32}$.

Por el contrario, en los textos aljamiados en alfabeto árabe se advierte una inclinación considerable hacia la notación fonológica, sobre todo si tomamos en cuenta la dirección de la evolución grafemática que se percibe al comparar una variedad de manuscritos ${ }^{33}$ : evolución que queda naturalmente truncada con la expulsión de los moriscos en 1609. Se admite que la aproximación al ideal fonológico no se logra en todos los textos aljamiados en la misma medida; pero algunos dejan entrever una clara intención de crear un sistema en ese sentido. Tal meta era evidentemente difícil de conseguir en el siglo XVI, época de transición fonológica. No existiendo además ninguna institución oficial entre los moriscos españoles que impusiese una norma, sería un error juzgar estos empeños con los criterios científicos de nuestros días.

Los textos aljamiados islámicos, por lo demás, nos ofrecen un interesante ejemplo adicional para ilustrar con claridad la manera de actuar del superestrato grafemático, y la tendencia hacia la formación de un Schriftbund. Conforme a las características fonológicas del árabe clásico, la sílaba árabe no puede comenzar por dos consonantes agrupadas. Aunque esta característica no es compartida ni por el español ni por otras lenguas a las cuales se ha aplicado, al emplear el alfabeto árabe, los amanuenses aljamiados suelen intercalar signos vocálicos, en calidad de auxiliares, entre dos consonantes agrupadas al comienzo de una sílaba, a pesar de que la

30 Más detalles sobre los signos dıacríticos se encuentran en FOULCHÉ-DELBOSC; art. cit., p. 23, y en RAYMOND RENARD, "L influence du mode de transcription sur le système phonique du judéo-espagnol", $R P h A, 2$ (1966), p. 38.

31 Según FOLLCHÉ-DELBOSC (p. 23) dhaled con rafé representa la /d/ intervocálica de los participios pasados en -ado, -ido, y la /d/ final de palabra. Se trataría, por lo tanto, de una variante en distribución complementaria. Aunque en algunos textos aljamiados islámicos al lado de $d \bar{a} l$ aparece también $d \bar{a} l$ para representar el fonema /d/, tal vacilación se da sólo en algunos textos. Por lo demás la alternancia de $d \bar{a} l$ y $\underline{d} \bar{a} l$ no parece obedecer a un principio determinado, y así nos inclinamos a creer que se trataría más bien de un caso de distribución libre.

3: FOLILCHÉ-DELBOSC, art. cit., p. 27.

33. Así el $\breve{s i n}=\langle\check{s}>$ que en ciertos documentos tempranos tiene una función bivalente, correspondiendo tanto a $/ \mathrm{s} /$ como a $/ \mathrm{s} /=\langle\mathrm{x}\rangle$ (de la antigua ortografía), en los textos tardíos se distingue sistemáticamente mediante el signo tašdīd cuando equivale a $/ \overline{\mathrm{s}} /$. 
escritura árabe dispone de un signo indicador de la ausencia de vocal: el sukun. En textos aljamiados españoles aparecen, por lo tanto, formas como taraidor, 'traidor'; nuestoro, 'nuestro'; garande, 'grande'; kiristiyano, 'cristiano', etc. El mismo fenómeno se da también en textos aljamiados portugueses ${ }^{34}$. Lo que resulta más sorprendente aún es que estos casos no son privativos de los textos iberorromances, sino que a parecen igualmente en textos aljamiados servocroatas ${ }^{35}$. Así, se documentan formas como tarūd, 'trud'; tereš$n a^{h}$ 'trešnja'; qirišqa ${ }^{h}$, 'kriška', etc. A base de las características métricas de composiciones poéticas se ha llegado incluso a sospechar que tales vocales llegaran a pronunciarse. Por fin, existe un manuscrito alemán escrito en alfabeto árabe ${ }^{36}$ que tiene la misma idiosincrasia, apareciendo en él formas como fališer, 'falsch'; gerin, 'gern'; galauben, 'Glauben', etc.

En nuestra presente discusión de los tres alfabetos hemos tratado de limitarnos al aspecto grafemático, sin extendernos a los préstamos, calcos u otras influencias de las lenguas de cultura que sirvieron de modelo a los tres grupos étnico-religiosos de la "España de judíos, moros y cristianos". Resumiendo, podemos afirmar que de la misma manera que los textos escritos en caracteres latinos, los que lo están en alfabetos orientales enlazan también el iberorromance con determinados ámbitos culturales que, a su vez, imprimen sus huellas en los varios niveles del sistema lingüístico.

En cierto sentido, nos encontramos frente a una situación parecida a la del hindustani, con sus variantes islámica e hindú —el urdu y el hindi-, transcrito éste en caracteres devanágari, y en árabes aquél. Se admite que las diferencias entre las modalidades cristiana, islámica y hebrea del iberorromance acaso no lleguen a semejante grado de separación, pero potencialmente llevan en sí el germen de una diferenciación lingüística ocasionada por motivos religioso-culturales.

Por último, cabe añadir, que en casos de multialfabetismo, los textos escritos en los diversos alfabetos se relacionan estrechamente con una específica tradición y contenido espirituales, de tal forma, que el inventario de grafemas y la estructura del sistema de escritura, junto con otros elementos lingüísticos, en una simbiosis de forma y fondo, se integran con la visión del mundo de las comunidades respectivas.

OtTMAR Hegyi

University of Toronto, Mississauga.

${ }^{34}$ DAVID LOPES DE MELO, Textos em aljamia portuguesa, Lisboa, 1940. El autor no llama la atención específicamente sobre este fenómeno, peroentre sus ejemplos se encuentran los casos de $t^{e}$ relado, $q^{e}$ rélito 'crédito' (p. 15), y $t^{i}$ irinta 'trinta' (p. 19).

${ }^{35}$ OTTO BLAU, Bosnisch-türkische Sprachdenkmäler, Leipzig, 1868.

${ }^{36}$ Literaturdenkmäler aus Ungarns Türkenzeit, ed. by Franz Babinger, Robert Gragger, Eugen Mittwoch, and J. H. Mordtmann, Berlin-Leipzing 1927, pp. 115-119. 